\title{
Preparation of International Business Negotiation Strategies: Competitive Assessment Aspects in The Market Power System
}

\author{
Kęstutis Peleckis ${ }^{1}$,Valentina Peleckienè ${ }^{1 *}$, Kęstutis K. Peleckis ${ }^{1 \mathrm{c}}$, Giedré Lapinskienè ${ }^{1 \mathrm{~d}}$, \\ Zlatko Nedelko ${ }^{2 \mathrm{e}}$ \\ ${ }^{1}$ Vilnius Gediminas Technical University, Sauletekio av. LT-10223 Vilnius, Lithuania \\ ${ }^{2}$ University of Maribor, Razlagova 14, SI-2000 Maribor, Slovenia
}

\begin{abstract}
The existence of exclusive rights to produce or supply services means a monopoly. Often it is called a natural monopoly. Exclusive rights are granted for a long period of time, which should encourage major investments in infrastructure, the development of which is unlikely to occur without a guaranteed market. But sometimes exclusive rights are used in situations where there is no natural monopoly. Exclusive rights are, in many respects, one of the main routes to market. Exclusive rights may allow monopoly pricing and other market power tools. Regulatory measures used by competition authorities alone do not make it possible to avoid such a situation, as they often show a very low success rate in preventing market power from being used to protect consumers. The purpose of this article is to analyze the theory and practice of preparing negotiating strategies in a complex way, to reveal opportunities to develop and implement these negotiating strategies, taking into account competition policy actions. The subject of the study is the preparation of negotiation strategies taking into account competition policy actions in the market. The research problem of the article - there is not enough tools in the negotiation theory to help develop negotiation strategies in line with competition policy actions.
\end{abstract}

\section{Introduction}

Competition policy influences the balance of bargaining power of market participants. Competition policy can provide additional opportunities and alternatives, thus reducing the negative impact of distorted competition on the balance of bargaining power of negotiators. However, there is another problem in this case - the extent to which competition policy should be applied, taking into account the influence of the balance of bargaining power of market participants.

The aim of the article is to analyze the theory and practice of negotiation strategy development in a complex way, to reveal possibilities for development and implementation of these strategies, taking into account competition policy actions.

\footnotetext{
*Corresponding author: valentina.peleckiene@ vgtu.lt
} 
The subject of the study is the preparation of negotiation strategies, taking into account competition policy actions. The research problem - there is not enough tools in the negotiation theory to help develop negotiation strategies in line with competition policy actions.

\section{Competition policy and its regulatory measures}

It is argued that trade liberalization (in this case openness in product markets) is mutually beneficial and depends on effective interaction between different markets. If product markets are not competitive or if market signals do not adequately reflect social costs and benefits (i.e., external outcomes), then the positive impact of openness can be rather low or absent. In some cases, policy remedies are needed to overcome these shortcomings, as it is often not enough to create an open competitive environment alone. In fact, under certain circumstances, openness can reinforce inefficiencies at the relevant external action or certain market specifics $[9,3]$.

\subsection{Granting Exclusive Rights}

The existence of exclusive rights to produce or supply services means a monopoly. Often it is called as a natural monopoly. Exclusive rights are given for a long period of time, which should encourage substantial investments in infrastructure, the development of which is unlikely to occur without a guaranteed market. But sometimes exclusive rights are used in situations where there is no natural monopoly. Exclusive rights are, in many cases, are one of the main routes to market. Exclusive rights may allow monopoly pricing and other market power tools. To avoid such a situation with regulatory measures alone is not possible, as they often show a very low success rate in preventing market from power being used and to protect consumers [12].

\subsection{Licenses or permits}

The relevant licenses or permissions of activity are restricting possibility to market access. Qualification requirements may include minimum standards of experience and education, and also may include requirements of good repute. In the field of finance, various aptitude tests are common in the pursuit of official duties within a company or its board. In some cases, may be a fixed number of licenses [12]. The requirements of license or permit often are stricter than necessary for consumer protection, and this can reduce opportunities of consumers and create artificial shortages, deficits that increase prices. When licensing schemes are often based on consumer protection objectives, such barriers to entry often protect local producers from competition. It is important to ensure that license and permit requirements do not burden the situation more than is necessary and would help to achieve the desired regulatory objectives [12].

\subsection{Geographical constraints}

Rules sometimes limit the flow of goods, services, capital and /or labor across the borders of different countries [13]. However, such restrictions artificially reduce the geographic scope of competition for the provision of goods or services. This may reduce the number of suppliers that can participate in the negotiations and potentially allow for other suppliers to use market power and increase prices. Potential limitations should be assessed in terms of whether there is a clear link between the constraints and the achievements of specific policy objectives, whether the restrictions are minimally necessary to achieve the objective, or whether a reasonable analysis indicates that the policy objective will be achieved. When 
limited restrictions apply for a limited period of time, with clear regulatory provisions, there is a high risk that "temporary" safeguards will be considered as semi-permanent arrangements as a result of supplier lobbying, enabling them to get profit from these restrictions [13].

\subsection{Limiting the number of suppliers}

The limited number of suppliers that can participate in the negotiations leads to the risk of creating exceptional market power and will be reduced natural competition [13]. When the number of suppliers decreases, because of the reduced competition (or agreements) between the remaining suppliers, increases the likelihood that prices will increase. The resulting reduction in competition can reduce the tendency to solve customer problems effectively and can reduce innovative and long-term economic efficiency. The existence of exclusive rights to produce or provide services is always linked to a corresponding monopoly. Often it is called as a natural monopoly. It is not possible to avoid such situations completely by regulatory measures alone, as, as practice shows, they often reach a very low success rate by preventing the use of power on the market, thus protecting consumers. It is important to ensure that license and permit requirements do not complicate the situation more than is necessary and help to achieve the desired regulatory objectives $[13,6,14,4,5,17,1,15,16,2]$.

\subsection{Determining the limits of competition}

Governments often regulate prices in traditional monopoly sectors, for example in the public sector [13]. Such price control is beneficial to consumers and is a counterbalance to the lack of alternatives to consumers. However, price control sometimes is applied in cases where the consumer may have many potential suppliers. When minimum prices are set, suppliers with lower prices are prevented from negotiating and gaining market share, giving consumers better value. Similar situation is in setting the highest prices - in such cases can be significantly reduced the incentives of suppliers to innovate and deliver new and /or high quality products [13]. Minimum price regulation is sometimes a response to extreme price competition [13]. In such cases, the regulation of minimum prices is generally considered to be a tool for protecting small suppliers against "unfair" competition. The highest pricing requirements are often introduced as a consequence of a restriction on admission. The alternative is to allow more market access. Price regulation is rarely the most effective or efficient way to achieve the intended goals [13].

\subsection{Advertising restrictions}

Often exist rules that limit suppliers' ability to advertise or sell goods, in order to limit false or misleading advertising. Occasionally, advertising restrictions are designed not to promote those services or products that are considered to have a socially negative value or are over-consumed [13]. However, practice shows that in many cases advertising and marketing restrictions are too broad and are too restrictive for competition. Restrictions of advertising and marketing can be particularly painful for potential market participants, as they limit the ability of a participant to inform potential customers about their presence in the market and the nature and quality of the goods and services being offered. In general consumer protection laws almost always contain misleading and deceptive advertising bans [13]. This promotes the efficiency of the markets and, in most cases, prevents any additional advertising restrictions on products or services. When there is a need to discourage over-consumption, alternative approaches to advertising restrictions include information campaigns [13]. 


\section{Coordinated behaviour of competitors}

Collusive agreements in competitive systems are considered illegal under competition law [11]. The alleged agreement can also be equally harmful. There is a debate about the differences between clear and implicit collusion and whether the enforcement of competition could be guided by an implied agreement [11]. Oligopolies are common in many sectors of the economy [11]. In these markets, there are relatively few companies that are interdependent and can influence the market price to some extent. Recognizing this understandable interdependence, profit-making companies in oligopolistic markets tend to take rational behavior and predictable behavior from competitors by setting prices and other competitive variables. When oligopolistic companies interact in the long term, they can maintain competitive prices, undermining consumer welfare and economic efficiency [11]. Cartel laws prohibit companies from explicitly restricting competition [11]. However, such an agreement may not be necessary for companies to coordinate successfully their behavior. The agreement can be implemented in a variety of ways, from a well-organized structure to a minimum or even to no communication between the parties [11]. While there are legal measures to tackle with a clear agreement, however it is being considered whether special measures are needed and how to deal with oligopolistic markets when there is no evidence of competitiveness-reducing action.

In this case, there is a risk that anticompetitive behavior will be invisible and, conversely, too strong action can destroy competitive behavior [11]. Cartel laws record a clear fact that companies have concluded an agreement [11]. There are also special tools for defining an implied agreement in some situations. However, these tools work in different economic and legal environments and do not allow to draw general conclusions about their usefulness. The legal term "agreement" or "coordinated actions" is quite broad, at least in substance, and may include parallel conduct [11]. In practice, for proof of coordination, requires among other factors, the evidence of links between alleged mergers. Some scientists say that the approach to agreements can be too formal and too dependent on communication. Some jurisdictions recognize the notion of "collective" or "common" concept of dominance. In principle, these provisions could be used to ban group abuse that would help them to keep silently secret results [11].

In some jurisdictions, authorities of competition may, under certain conditions, impose coordination between companies in cases of parallel price increases [11]. This presumption of the agreement aims to reduce the burden of proof on the competition authority. This assessment takes into account such things as the characteristics of the goods or services, the impact of the relevant practices, and the frequency and form of contact between companies [11]. Alternative methods include legislation for specifically simplified practices, such as disclosure of price information to competitors, or cases of concentrated market structure [11]. Discussions reveal that the defense of competition is also important in oligopolistic markets where, for example, regulation can limit the number of competitors or influence their incentives. Market research helps to analyze competition in oligopolistic markets. They can provide useful insights or evidence for further action. In some jurisdictions, public authorities have the power to conduct market research and use the means of rights defence if they have a negative impact on competition. Market research is a useful complementary tool and does not change competition law enforcement [11]. Competition authorities conduct market surveys where there are concerns that the market or sector may not function properly for a variety of reasons, including market structure, behavior or information. Market research can be useful for existing oligopolistic markets. One Competition Authority may see the damage if there is a presumption that the companies conduct coordinated behavior.

Merger control provides a potential predictable solution on implied agreements [11]. Competition authorities can correct or prohibit mergers that could facilitate market 
coordination. However, few mergers are contested on the basis of the results of the coordinated impact assessment. Indeed, mergers can lead to coordinated behavior and have a significant impact on prices and consumer welfare [11]. Merger control is a priority tool to combat with implicit coordination in oligopolistic markets. There are several reasons why agencies can give priority to merger control, as this is a key tool focused on the supposed interpretation of a collusive outcome. However, merger control does not solve all competition problems in oligopolies. For example, companies may be implicitly bound by mutual agreements and obligations even in the absence of a merger. On the other hand, not all mergers can be reviewed under the laws of jurisdiction. In addition, coordinated effects, results can be hard to prove [11]. The analysis of coordinated impacts in a merger usually involves two stages [11]:

- an assessment of whether in related markets, where the merger took place, it is useful to coordinate actions;

- an assessment of whether the merger would lead to such coordination. Factors used to assess whether the market favors coordination include market concentration, uniformity of products, market transparency and coordination history. These factors may sometimes produce different results and are difficult to weigh. The assessment of the impact of the merger on coordination is based on the same factors. For example, coordination can be easier in a market with fewer businesses. When a merger implies that it will be strongly coordinated, for example due to the emergence of new economic incentives, the merger may increase the likelihood of coordination between companies [11].

Various merger modeling techniques may be used to compare the benefits of collaboration in pre- and post-merger analysis of results [11]. These methods enable to measure the extent of potential incentive to collaborate, but do not prove that companies have actually cooperated. It is claimed that models and quantitative evidence used in predicting coordinated effects in mergers are not more complicated than those used for unilateral impact analysis, and are not stricter in terms of data requirements. However, in case of coordinated exposure scenarios, merger modeling may not give any clear indication of price increases expected after the merger [11].

Scientific discussions highlight that quantitative modeling should be used as an additional or separate analysis, as is done in the cases of unilateral effects [11]. For example, competition authorities could rely on similar documents created for specific business conditions, indicating that companies are trying to coordinate. Competition authorities can also rely on theories of consistent damage based on solid, but not necessarily complex, models. Limiting the number of negotiators leads to the risk of creating exceptional market power and will decrease natural competition. When the number of suppliers decreases, because the reduced competition (or agreements) between suppliers, increases the likelihood of price growth. The resulting reduction in competition can reduce suppliers' ability to address customer problems effectively and can reduce innovative and long-term economic efficiency [12].

\section{Abusive discrimination and divisional strategies to alleviate it}

Many countries have rules that allow competition authorities to fight against abusive price discrimination and strategies that facilitate it [13]. Since market power is an opportunity to raise the price beyond the marginal cost, which can be acquired, strengthened, preserved and used, it is traditionally a type of one side behavior. Abusive price discrimination is behavior where a company or group of companies with significant market power sets prices that maximize its profits [13]. This does not reduce the degree of market power and leads to monopolization. However, there are unacceptable actions (or "distribution strategies") that can help a dominant company not to increase profit, but to change the cost (s) of profit 
increase. Here, actions are organized according to price discrimination schemes, which allow companies to increase their markups, and at the same time increase market power and thus create a "more powerful monopoly" [13]. What does these strategies cover? They may include measures to prevent arbitrage or group customers, as well as collect and analyze data on individual consumers' willingness to pay for products [13]. These activities may be used by the company to share the market, increase average revenue and market power. If this exploitation (which may or may not be reinforced by the division strategy) occurs in the upstream market, there is a risk that such behavior is distorting competition.

The unilateral conduct of rules in the markets by most jurisdictions is based on the enforcement of the principles of consumer protection. Price discrimination at least in dominant companies can lead to a redistribution of consumer surpluses from consumers to shareholders, which will at least in the short term harm consumers [13]. Dynamic incentives for businesses to increase their profits will not always benefit consumers. There may also be "loopholes" where companies create market power because of anti-competitive mergers or behavior that was implemented through loopholes in rules [13]. While it is likely, that rational consumers will be able to protect themselves against corporate price discrimination. Companies with such market power may be concerned that consumers with bias in their behavior may want to pay more than they want to pay for the product (artificially shifting the demand curve to the outside) and that market power can increase this risk [13]. It can be assumed that markets can build on and manage self-regulation. In this case, the damage to consumers can take longer than a short time. For example, even if entry barriers are low, the monopolist may still be able to continue to apply the relevant prices as it may take longer for other companies to start up and become competitive. When exploitative price discrimination occurs between buyer intermediaries, there may be a negative impact on consumer supply. For example, end-users of an unfair intermediary will likely pay higher prices if the broker becomes discriminated against at the end-user (even if it is a relatively small part of the final price) [13].

\section{Efficiency in allocation of resources and coordination of competition policy}

A certain group of scientist economists say that market exchanges - when choices of people reflect values and companies choose their biggest profits - the limited resources are effectively distributed. Efficiency in this sense requires that individual buyers and sellers will not be able to influence the price, exchange of which is taking place on the market. In addition, markets must exist for all goods. It is argued that if these conditions will be met, markets will be competitive and comprehensive, this will be an efficient allocation of resources [9]. These conditions are rarely satisfied. Here are some examples of unsatisfactory conditions [9]:

- Some companies can control the price because there are too few competitors or because the products they sell have brand names that allow the seller to control the price. Companies can also control prices if they work in secret;

- Information flows may be biased.

For example, asymmetric information between buyers and sellers can significantly reduce market transactions;

- Consumption can sometimes be seen only in terms of the consumer. Others may also have benefits. This may be a case of positive externalities. On the contrary, the company cannot assess its production costs alone, for example, the environmental damage caused by production must also be taken into account. In this case, there is a negative impact on the 
outside, as the cost to society of producing that particular product is higher than private expenditure.

Even if there is no market failure, the functioning of the economy can distribute income in one way or another. This is often due to unequal distribution of wealth and unequal opportunities. Policies aimed at reallocating assets and creating equal opportunities (for example, education, health, etc.) can help to achieve socially acceptable allocation of assets without major distortions of markets and incentives. The above market failure conditions are necessary (but not sufficient) conditions for public action. However, it is important to analyze public actions and effective policy making and their interaction with production and trade [9].

\subsection{Context of coordination competition policy}

Few areas need to be highlighted when discussing competitiveness policies.

First, greater resource allocation efficiency is the prizm, through which we value the consistency of trade, competition and environmental policies. Trade liberalization focuses on perfect markets - to allocate resources to the most productive markets and targeting them for the most efficient use. This happens when countries specialize in producing those goods and services where they have comparable competitive advantages. The main objective of competition policy is to limit operations of companies in the market. The motivation of company that is maximizing profit can create barriers between alternative costs and prices paid by consumers. The purpose of the correct allocation of environmental resources is to ensure that people appropriately value these resources and do not keep free goods. The coherence of trade, environmental and competition policies must therefore be assessed in terms of the contribution to resource allocation and efficiency use.

Secondly, the international dimension of competition and environmental policy is important. For example, in the case of cross-border mergers, conflicts may arise due to differences in competition regulatory frameworks and principles. Evaluation of different merger cases can lead to different results. In order to develop international, global trade, international cooperation between competition authorities is needed.

International cooperation is also needed when the competition problem is global in nature, such as cases of international cartels, where prices are set to affect consumers in national markets. When environmental impacts are global rather than national, international cooperation is the most effective way to manage the problem. International compatibility is also needed to avoid conflicts between different international legal systems, such as multilateral environmental agreements and multilateral trade rules.

Third, the whole is more than the sum of its individual parts. Trade, environmental and competition policies individually promote resource efficiency. But the policy in each individual area is less effective, among other policy measures. The country will not benefit from maximum open trade if domestic law allows non-competitive behavior of domestic companies. There is no strong evidence that a country with the strongest competition rules is relinquishing significant structural and dynamic competitive advantages. While the focus is on optimal policies that complement openness to trade, public action is not a panacea for all disasters. Although in many cases the market power of an enterprise is generally undesirable in the market, it may be the only possible result in terms of consumer tastes or technological realities. For example, mergers can bring economic benefits through economies of scale and the sharing of know-how, as they can increase the market power of the merged entity. Regulators can regulate and prohibit such compounds. Compliance with regulations also requires the development of appropriate expenditures, including preparing of regulations. Environmental rules need to be monitored and enforced, so it is necessary to spend and use certain resources. When deciding on state intervention for external factors, 
the costs of government action must also be considered. While the move towards a more open economy increases competition, the opportunities for domestic and foreign companies to apply anti-competitive practices are not necessarily reduced. Indeed, in some cases, internal competitiveness may even increase. Alternatively, foreign firms may behave in an anti-competitive manner when trying to enter the market. In any case, the development and implementation of an effective competition policy is mandatory. Given the competition concerns that do not fall within the review of the domestic authority alone, more extensive actions are needed. International competition problems increasingly require international solutions. The scope of such decisions, including whether they must be legally binding, is rather broad. Over the last decade, the focus has been on the interaction and relationship between competition and trade policy. There are good reasons for this, especially when both policies are considered to have the same objective of creating and promoting active and competitive markets. Trade policy aims to reduce the tariff and non-tariff barriers imposed by governments. On the other hand, competition policy pursues the ultimate goal of limiting actions between companies and their groups, making obstacles for competition [9].

\section{The objectives of the competition policy, market structure and openness}

Traditional market research methods usually analyze the number and size of companies. The larger the number of companies, the more competitive industry is. This approach has changed in the early 1980s and created a more complex understanding of industrial organizations. Instruments borrowed from game theory have been developed to accommodate new insights into corporate behavior. Instead of focusing on the number and size of industry, attention has been focused on their behavior, and in particular on barriers to market entry. In order to understand better barriers to market entry, a monopoly case study begins. If there is only one company in the industry, it limits the output and increases the price of the product to maximize its profits. The big profits of this company encourage other companies to enter the industry. Under the scenario that they can enter the industry, the current monopolist would be forced to change prices and production behavior. Perhaps it would be reasonable to expect the current monopolist to change its commercial behavior as a matter of priority if the new entrant has strong arguments to enter the industry. The reliability of this signal is highly dependent on the level of barriers - the lower the barriers to market entry, the stronger the opportunity for a new entrant to enter the market. On the contrary, the higher the barriers to entry, the less opportunities [9].

Two barriers to entry can be addressed - regulatory and structural barriers. Regulated barriers are often linked to government policies to restrict or control access to industry. This includes requirements to obtain permits or licenses to participate in a particular market. In some cases, permission may be allowed, but such costs may be excessive. Other examples of regulatory barriers to competition are measures that reduce or prohibit imports, such as tariffs or quantitative restrictions. Not all barriers to entry come from governments. In many cases, the obstacles can also be structural in nature. For example, a particular industry can make the necessary investment in a company. In such a case, the costs incurred can cause a loss when the exit to a new country can be quite difficult, in which case the risk of arrival is quite high. Similarly, there is a high fixed entry cost, which can discourage entry. Other potential structural barriers include economies of scale and network effects. As regarding structural barriers to market entry, there are also cases where structural barriers to market entry are such that only one company in the market can function effectively. Examples of such natural monopolies can be found in industries that require large-scale investment, such as distribution networks, electricity generation, and so on. In these cases, political decisions 
cannot facilitate market access, as this will make no sense. Instead, the behavior of natural monopolists must be regulated in such a way as to balance the public interest in obtaining a product on the market, also taking into account the commercial interests of natural monopolists [9]. Other barriers to entry may be related to the current operator's reaction to the emergence of a new competitor. Even if the regulatory and structural barriers were minimal, the current company could take advantage of its potential to reduce competition. For example, pricing policies can be both aggressive and malicious [9].

Effective competition policy is an important basis for an efficient economy. So far, there is no unified approach to competition policy. Different countries use different methods. In some countries, there is wide-ranging legislation on mergers, reviews of merger procedures, dominance assessments of companies or groups of companies and anticompetitive practices, while in others, basic pricing legislation is adopted. Competition policy should be understood in a broad sense and should be seen as covering not only antitrust policy, but also other competition policies that have an impact on market structure, business unit behavior and economic activity [9].

It is sometimes argued that the objectives of competition policy can be achieved, at least in part, in open trade and investment policies. For example, a small open economy can stimulate the development of competition by allowing foreign suppliers to work in their markets. It is likely that an open investment policy will reduce the ability of national industries to manage markets and obtain monopoly prices. The validity of the argument that open trade and investment policies can change competition policy is based on the assumption that external effects will eliminate anti-competitive market structures. This may not always be the case.

Increasing of market openness is not always able to increase competition between companies - in fact, even a reverse situation can occur, and it may occur in some circumstances. So the role of competition policy is very important. Some industries are less competitive than others. Due to the high immediate costs of such industries as electricity or water supply, intervening in such a market is difficult, and the market is unlikely can to create competitive structures with or without foreign participation. In such cases, regulatory action on competition is important [9]. When buyers have a choice between different suppliers, both they and the economy as a whole will win [8]. Their ability to choose encourages companies to compete with each other. Choosing for buyers is beneficial, and not only for them, competition between companies leads to increased productivity and economic growth. Most importantly, sectors with more competition are experiencing faster productivity growth. The impact of stronger competition in a particular sector may also be felt in other sectors. For example, there may be productivity gains in the service sectors and an increase in the level of employment, and this can spread much more widely across the economy [8]. The main reason is that competition encourages more efficient allocation of funds, so more efficient companies can enter the market and gain market share at the expense of less efficient companies. Therefore, regulations or anti-competitive behaviour that impede market access and development can be particularly damaging to economic growth. Competition also improves the efficiency of productive companies, as competitive companies are better managed [8]. Also, competition encourages innovation. Companies face competition and innovate more often than monopolies [8]. However, such companies can also obtain a patent monopoly. Moderately competitive markets are the ones that are most innovative, as both the monopoly and highly competitive markets show weaker innovation. However, as competition policy focuses on increasing the competitiveness of insufficiently competitive markets, and the introduction or strengthening of competition in the markets where they are not yet functioning, it still means that competition policy is strongly driven by innovation [8]. 


\section{Conclusions}

1. The existence of exclusive rights to produce or supply services constitutes a monopoly, which is often referred to as a natural monopoly. Exclusive rights are granted for a long-term period, which should encourage substantial investment in infrastructure, which is unlikely to occur without a guaranteed market. But sometimes exclusive rights are also used in situations where there is no natural monopoly. Exclusive rights are, in many respects, one of the main ways to enter the market. Exclusive rights can give rise to monopoly pricing and other issues related to the use of market power. This cannot be completely avoided by regulatory measures alone, as these measures often reach a very low success rate by preventing the use of power on the market, thereby protecting consumers.

2. A limited number of supplier markets lead to the risk of creating exceptional market power and less natural competition. As the number of suppliers decreases, the reduced competition (or agreements) between the remaining suppliers increases the likelihood that price will increase. The resulting reduction in competition can reduce suppliers' ability to address customer problems effectively and can reduce innovative and long-term economic efficiency.

3. Licenses or authorizations shall restrict access to the market. Qualification requirements may include minimum standards of experience / education and may include requirements of good repute. In the field of finance, various aptitude tests are common in the pursuit of official duties within a company or its board. In some cases, a number of licenses may be fixed. License or permit requirements are often stricter than necessary for consumer protection and can unnecessarily reduce consumer opportunities and create artificial flaws that increase prices. Licensing schemes are often based on consumer protection objectives, and entry barriers often protect local producers from competition. It is important to ensure that license and permit requirements do not complicate the situation more than is necessary and help achieve the desired regulatory objectives.

4. Two barriers to entry can be identified - regulatory and structural barriers. Regulated barriers are often linked to government policies to restrict or control access to industry. This includes requirements to obtain permits or licenses to participate in a particular market. In some cases, permission may be allowed, but such costs may be excessive. Other examples of regulatory barriers to competition are measures that reduce or prohibit imports, such as tariffs or quantitative restrictions. Not all barriers to entry come from governments. In many cases, the obstacles can also be structural in nature. For example, a particular industry can make the necessary investment in a company. In such a case, the costs incurred can cause a loss when the exit to a new country can be quite difficult, in which case the risk of arrival is quite high. Similarly, there is a high fixed entry cost, which can discourage entry. Other potential structural barriers include economies of scale and network effects. As regards structural barriers to market entry, there are also cases where structural barriers to market entry are such that only one company in the market can function effectively. Examples of such natural monopolies can be found in industries that require large-scale investment, such as distribution networks, electricity generation, and so on. In these cases, political decisions cannot facilitate market access, as this will make no sense. Instead, the behavior of natural monopolists must be regulated in such a way as to balance the public interest in obtaining a product on the market, also taking into account the commercial interests of natural monopolists [9].

5. An effective competition policy is an important basis for an efficient economy. So far, there is no unified approach to competition policy. Different countries use different methods. In some countries, there are wide-ranging legislation on mergers, reviews of merger procedures, dominance assessments of companies or groups of companies and anticompetitive practices, while in others, basic pricing legislation is adopted. Competition policy should be understood in a broad sense and should be seen as encompassing not only 
antitrust policy but also other competition policies that have an impact on market structure, business unit behavior and economic activity.

6. Scientific literature sometimes states that the objectives of competition policy can be achieved, at least in part, in open trade and investment policies. The validity of the argument that open trade and investment policies can change competition policy relies on the assumption that external effects will eliminate anti-competitive market structures. This may not always be the case. Increasing market openness is not always able to increase competition between companies - in fact, even a reverse situation can occur, and may occur in some circumstances. So the role of competition policy is very important.

\section{References}

1. Y. Chen, M. Tanaka, Permit banking in emission trading: Competition, arbitrage and linkage, Energy Economics, 71, 70-82, ISSN 0140-9883 (2018)

2. M. Gámez, I. C. Rodríguez, Z. Varga, J. Garay, Game-theoretical model for marketing cooperative in fisheries, Applied Mathematics and Computation, 329, 325-338 (2018)

3. S. Ghosal, S. Tonin, Noncooperative Oligopoly in Economies with Infinitely Many Commodities and Traders, Games and Economic Behavior (2018)

4. L. Kaplow, Price-Fixing Policy, International Journal of Industrial Organization (2018)

5. P. Kumar, Market Power and Cost Efficiencies in Banking, International Journal of Industrial Organization (2018)

6. Q. Liu, L. F. S. Wang, C. L. Chen, CSR in an oligopoly with foreign competition: Policy and welfare implications, Economic Modelling (2018)

7. N. Madeikytè, Tiesiniai modeliai Nešo pusiausvyrai rasti. 14-osios Lietuvos jaunujų mokslininkų konferencijos „Mokslas - Lietuvos ateitis“, 1-4 (2011)

8. OECD. Factsheet on how competition policy affects macro-economic outcomes. (2004)

9. OECD. Market definition. DAF/COMP(2012)19 (2012)

10. OECD. Recommendations for combating bid falsification in public procurement. (2014)

11. OECD. Competition enforcement in oligopolistic markets. DAF/COMP. (2015)

12. OECD. Competition assessment toolkit. Principles. 1. (2016)

13. OECD. Defining geographic markets across national borders. DAF/COMP/WP3(2016)5. (2016)

14. R. Schlosser, Stochastic dynamic pricing and adve tising in isoelastic oligopoly models, European Journal of Operational Research, 259, 3, 1144-1155 (2017)

15. G. Symeonidis, Collusion, profitability and welfare: Theory and evidence, Journal of Economic Behavior \& Organization, 145, 530-545 (2018)

16. T. Uchiyama, Quasi-competitiveness in the Cournot model with heterogeneous firms, Economics Letters, 165, 62-64 (2018)

17. Y. Yasui, J. Haraguchi, Supply function equilibria and nonprofit-maximizing objectives, Economics Letters, 166, 50-55 (2018) 